\title{
The Knowledge and Participation of the Father in Breast Feeding, Salvador, Brazil
}

\author{
Fernanda Tourinho Lima, Andréa Canário Santana, Gilton Marques dos Santos, \\ Tatiane Falcão dos S. Albergaria, Luciana Rodrigues Silva
}

Universidade Federal da Bahia, Salvador, Brazil

Email: fernanda.cms.lima@hotmail.com

How to cite this paper: Lima, F.T., Santana, A.C., dos Santos, G.M., Albergaria, T.F. dos S. and Silva, L.R. (2016) The Knowledge and Participation of the Father in Breast Feeding, Salvador, Brazil. Open Journal or Obstetrics and Gynecology, 6, 559-571. http://dx.doi.org/10.4236/ojog.2016.610072

Received: March 12, 2016

Accepted: August 23, 2016

Published: August 26, 2016

Copyright $\odot 2016$ by authors and Scientific Research Publishing Inc. This work is licensed under the Creative Commons Attribution International License (CC BY 4.0).

http://creativecommons.org/licenses/by/4.0/

\begin{abstract}
The most fundamental influence in the breastfeeding process is the father's support. The mother feels safer in breastfeeding when she has her partner's support and a more active and effective participation. This study aimed at evaluating the father's knowledge about breastfeeding in a quantitative approach through a transversal cohort study, interviewing 78 fathers in a public maternity in Salvador. The average age of the interviewees was 29.9 years and $53.8 \%$ had an incomplete fundamental schooling. Regarding knowledge of the subject, $10.3 \%$ believed that breastfeeding can be substituted. All fathers interviewed answered that they support breastfeeding for their children and believe in its benefits; $39.7 \%$ reported that their opinion could interfere their partner's decision to prolong the process. Moreover, $69.2 \%$ of the males attended their partner's antenatal meetings, and of these, over a third had no intervention on the subject. Of all the participants, $80.8 \%$ confirmed that they had participated in the breastfeeding process and emphasized their gratification during this phase. About the paternal opinion, $39.7 \%$ believed that there is a degree of influence over the partner's decision to breastfeed, and for that reason $50 \%$ told the mother their opinion. The study widened the knowledge about the role of the father in breastfeeding, ratifying the importance of their support towards the mother in this process, ultimately contributing to improving the practice and benefiting the mother-child relationship. Therefore, we conclude that those interviewed have some knowledge about breastfeeding, recognize its importance during the process and would like to know more.
\end{abstract}

\section{Keywords}

Father, Breastfeeding, Knowledge

\section{Introduction}

One of the main influences for the success of breastfeeding (BF) is represented by the 
support of the father [1]-[5], and this participation is highly regarded and essential in any community [6] [7]. The devaluation of breastfeeding by the father was identified as one of the main predicting factors for early interruption of this practice [8]-[13]. It should be emphasized that many of them are not aware or have enough information about their own importance, therefore hampering an adequate participation in the process of breastfeeding [14]-[16].

The feelings of a man in relation to his partner and child are one of the essential factors to determine the success in pregnancy and birth in all its phases, including BF [2] [3] [17]-[19]. The arrival of the new-born represents a great load of demands on the father; he is concerned with his ability to provide the family's needs, offer support to his partner, besides having time to look after himself [7] [14], despite Fletcher et al. (2008) [20] suggestion that breastfeeding might not be an attractive theme for fathers during their partner's antenatal process. That way, the man must contribute to this process with new functions, offering emotional support to his wife and caring for the baby, effectively participating in this phase [14] [19] [21].

The present research aims to understand the opinion of the fathers about their functions in breastfeeding and the importance of their support. The lack of studies conducted in Brazil focusing on this subject highlights the need to answer questions. The objective of the present study was to describe the knowledge of the father about breastfeeding and the influence of their participation.

\section{Methods}

This is a transversal study, carried out in the period from March to May 2014, in an important maternity in the state of Bahia, Brazil. All fathers who had their children born in that hospital and were present in the Common Ward (as companions or visitors) at the time, and agreed to take part when asked by the researcher were included in the study. As a non-inclusion criteria were those fathers whose new-borns (NB) were not staying in the common ward due to various clinical complications, or whose partners were admitted in another ward, also due to clinical complications, hampering the exclusive use of breast milk in the immediate afterbirth. Those fathers who refused to participate were also excluded.

Following the ethical aspects according to Resolution 466/12 of the National Health Council (CNS, abbreviation in Portuguese), a Free and Informed Consent Form (TCLE, abbreviation in Portuguese) was signed by the fathers who agreed to take part in the study.

The investigation tool used was an interview composed by two parts: the first one aimed at characterizing the participants, and the second aimed at evaluating the father's knowledge about the aspects of breastfeeding and the influence of their participation. A pilot project was carried out for internal validation of the interview.

The data generated from the subjective questions were organized and categorized in Microsoft Excel 2010, and used for registration and descriptive data analysis. The sample was of convenience, and as it wasn't probabilistic, no inferential statistics were calculated, 
due to the impossibility of an adequate estimative of standard deviation.

The project was approved by the Ethics in Research Committee of the University Hospital Professor Edgard Santos (HUPES), on March 14th 2014, under protocol No. 21731113.5.0000.0049.

\section{Results}

At the time of the research at the Common Ward, there were 85 males of which 78 agreed to take part. Four refused and three did not comply with the inclusion criteria (the baby of one father was at the Canguru infirmary and two others had their babies staying in the Neonatal Intensive Care Ward). Table 1 shows the description of the sample studied. Regarding the father's knowledge about breastfeeding (BF), artificial milk and complementary feeding, the results were expressed on Table 2. The data about the benefits for nursing mother and infant and the difficulty of breastfeeding were inserted on Table 3. The results regarding the answers analysing the role of the father in breastfeeding are shown on Table 4.

In this research, $28.2 \%$ of the fathers had knowledge of some techniques for the correct breastfeeding: the baby should be supported by the mother's body (10\% or $45.5 \%)$; the baby should be correctly adjusted on the arm - baby's head on the arm and the bottom supported by the mother's hand ( $9 \%$ or $41 \%$ ); baby should be inclined (5\% or $22.7 \%$ ); the baby's mouth should be stimulated to open (3\% or $13.6 \%$ ); the baby should be supported by only one arm/hand (3\% or 13.6\%); the baby should suck the whole breast ( $2 \%$ or $9.1 \%$ ); the mother should be seated when breastfeeding ( $2 \%$ or $9.1 \%$ ); others: hold the breast with a cupped hand, change breasts between feedings, massage

Table 1. Characterization of the fathers population (male gender), at the studied maternity-Salvador, Bahia, 2014.

\begin{tabular}{lcc}
\hline \multicolumn{1}{c}{ Characters } & Number of fathers $\%(\mathrm{~N}=78)$ & 6.8 \\
\hline Average age (years) & 29.9 & \\
Marital status & $19.2(15)$ & $14.1(11)$ \\
Married & $66.7(52)$ \\
Single & \\
Stable relationship & $5.1(4)$ \\
Level of education & $9.0(7)$ \\
Incomplete fundamental school & $53.8(42)$ \\
Complete fundamental school & $24.4(19)$ \\
Incomplete intermediate school & $3.8(3)$ \\
Complete intermediate school & $3.8(3)$ \\
Incomplete superior school & \\
Complete superior school &
\end{tabular}


Table 2. Knowledge of the fathers (male gender) about the duration of breastfeeding, artificial milk, complementary food, at the studied maternity-Salvador, Bahia, 2014.

\begin{tabular}{|c|c|}
\hline Knowledge & Number of fathers $\%(\mathrm{~N}=78)$ \\
\hline \multicolumn{2}{|l|}{ BF can be substituted by another food? } \\
\hline yes & $10.3(8)$ \\
\hline no & $89.7(70)$ \\
\hline \multicolumn{2}{|l|}{ Duration of BF (months) } \\
\hline$\leq 3$ & $1.3(1)$ \\
\hline $3-6$ & $17.9(14)$ \\
\hline $6-10$ & $11.5(9)$ \\
\hline $10-12$ & $17.9(14)$ \\
\hline $12-24$ & $28.2(22)$ \\
\hline$>24$ & $21.8(17)$ \\
\hline No answer & $1.3(1)$ \\
\hline \multicolumn{2}{|l|}{ Is there a period for exclusive $\mathrm{BF}$ ? } \\
\hline yes & $82.1(64)$ \\
\hline no & $17.9(14)$ \\
\hline \multicolumn{2}{|l|}{ Duration of exclusive BF (months) } \\
\hline$\leq 1$ & $10.9(7)$ \\
\hline $1-2$ & $4.7(3)$ \\
\hline $2-3$ & $18.8(12)$ \\
\hline $3-6$ & $51.6(33)$ \\
\hline $6-12$ & $14.1(9)$ \\
\hline \multicolumn{2}{|l|}{ Is there a need to introduce complementary food? } \\
\hline yes & $97.4(76)$ \\
\hline no & $2.6(2)$ \\
\hline \multicolumn{2}{|l|}{ When should complementary food be introduced? } \\
\hline As soon as the baby is born & $-(0)$ \\
\hline When the baby leaves hospital & $5.1(4)$ \\
\hline When the baby is six months' old each food has a time to be introduced & $52.6(41)$ \\
\hline After 2 years & $5.1(4)$ \\
\hline When the baby does not accept the mother's breast, at any age & $34.6(27)$ \\
\hline No answer & $2.6(2)$ \\
\hline \multicolumn{2}{|l|}{ Is artificial milk as good as BF? } \\
\hline yes & $2.6(2)$ \\
\hline no & $97.4(76)$ \\
\hline
\end{tabular}

the breasts ( $4 \%$ or $18.2 \%)$; no answer ( $1 \%$ or $4.5 \%)$. Among those who declared to have some knowledge for a correct breastfeeding technique, $27.3 \%$ of the answers were considered incorrect.

Among all men, $69.2 \%$ of those participated in the antenatal meetings during the 
Table 3. Knowledge of the fathers (male gender) about the benefits and difficulties of breastfeeding for the nursing mother and infant, in the studied maternity-Salvador, Bahia, 2014.

\begin{tabular}{|c|c|}
\hline Knowledge & Number of fathers $\%(\mathrm{~N}=78)$ \\
\hline \multicolumn{2}{|l|}{ Are there benefits in breastfeeding? } \\
\hline yes & $80.8(63)$ \\
\hline no & $12.8(10)$ \\
\hline no answer & $6.4(5)$ \\
\hline \multicolumn{2}{|l|}{ What are the benefits for the mother? } \\
\hline Empty the breasts/no waste/avoid petrified milk & $38.1(24)$ \\
\hline Relationship mother-child & $17.5(11)$ \\
\hline Prevent diseases/breast cancer & $12.7(8)$ \\
\hline Lose weight & $6.3(4)$ \\
\hline Afterbirth recovery/less complications & $4.8(3)$ \\
\hline Decrease expenses & $4.8(3)$ \\
\hline Other benefits & $6.3(4)$ \\
\hline No answer & $22.2(14)$ \\
\hline \multicolumn{2}{|l|}{ Are there benefits for the child in breastfeeding? } \\
\hline yes & $100(78)$ \\
\hline no & $-(0)$ \\
\hline \multicolumn{2}{|l|}{ What are the benefits for the child? } \\
\hline More resistance/improvement in immune system/health & $61.5(48)$ \\
\hline Development/growth & $50.0(39)$ \\
\hline Good nutrition/weight gain/best food & $26.9(21)$ \\
\hline Source of calcium/strong bones/strength & $23.1(18)$ \\
\hline Emotional bond & $6.4(5)$ \\
\hline Teething & $3.8(3)$ \\
\hline Other benefits & $16.7(13)$ \\
\hline No answer & $6.4(5)$ \\
\hline \multicolumn{2}{|l|}{ Breastfeeding brings benefits for the child in the long term? } \\
\hline yes & $70.5(55)$ \\
\hline no & $29.5(23)$ \\
\hline \multicolumn{2}{|l|}{ Did you notice any difficulties for the mother in breastfeeding? } \\
\hline yes & $62.8(49)$ \\
\hline no & $35.9(28)$ \\
\hline no answer & $1.3(1)$ \\
\hline \multicolumn{2}{|l|}{ Which difficulties were observed? } \\
\hline Pain & $34.7(17)$ \\
\hline Milk was difficult to come/not enough milk & $22.4(11)$ \\
\hline Cracks & $20.4(10)$ \\
\hline Nipple formation/incorrect holding & $20.4(10)$ \\
\hline Afterbirth movements/correct position & $16.3(8)$ \\
\hline Petrified milk/leaks & $6.1(3)$ \\
\hline First time anxiety & $6.1(3)$ \\
\hline Other difficulties & $6.1(3)$ \\
\hline No answer & $2.0(1)$ \\
\hline
\end{tabular}


Table 4. Knowledge of the fathers (male gender) about their role in the breastfeeding process, at the studied maternity-Salvador, Bahia, 2014.

Functions $\quad$ Number of fathers \% $(\mathrm{N}=78)$

Participated in the antenatal process during partner's pregnancy?

yes

no

Had interest in finding out how to help their partner to breastfeed?

yes

no

$41.0(32)$

$59.0(46)$

As a father, participates in the breastfeeding process?

yes

$80.8(63)$

no

$19.2(15)$

As a father, which is your participation?

Helps BF process

Guidance/observation of process

$33.3(21)$

Help in caring for the baby and home

Concern with the well-being/affection towards the mother

As a father, supports that your child is breastfed by the mother?

yes

no

Does your opinion interfere in your partner's decision to breastfeed for longer or less time?

yes

no

Which should be the changes for a higher level of male participation in breastfeeding?

Higher awareness/more paternal participation

Increase of paternal licence/holidays in this period

$11.5(9)$

More guidance for the fathers about $\mathrm{BF}$

$10.3(8)$

Creation of talks/courses for basic instructions for men

$9.0(7)$

More opportunities/time to participate

$3.8(3)$

Other changes

No answer

Suggestions to formulate a program to influence fathers to participate more in the breastfeeding process:

Dynamic programs/courses/talks/workshops

More incentive for fathers to participate in the antenatal

More information on the subject

$9.0(7)$

Articles/advertisements in the media to stimulate

$9.0(7)$

More guidance/information/theory and

practice classes in the maternities and common wards

Other suggestions

No answer

$26.9(21)$ 
pregnancy, and $90.7 \%$ (49) felt welcomed during these appointments when they could join. However, $79.6 \%$ of the men present in the meetings were not approached or had any advice or guidance regarding "how the father should or should not participate in breastfeeding". Of the $39.7 \%$ of fathers who had some guidance-during the antenatal meetings or outside-the information given included: how to help the mother to care/breastfeed the baby $(48.4 \%$ or $15 \%)$; the importance of father's affection $(3.2 \%$, or $1 \%)$; the benefits/importance of BF (29\%, or $9 \%)$; and the importance of the father in the antenatal meetings (3.2\%, or $1 \%)$.

In this study, $85.9 \%$ (67) of the men believed that the father should participate in some way in breastfeeding, and the reasons given were the following: the father's participation is important for the child ( $34.8 \%$ or $24 \%)$; it is necessary to support/help the mother when she is absent/unable $(30.4 \%$ or $21 \%)$; it is important to guide/stimulate/seek knowledge/follow the breastfeeding process (27.5\% or $19 \%)$. However, only $41 \%$ of those interviewed had any interest in finding out how to help their partners with breastfeeding. Based on this answer, the kind of participation they believe they should have involves: help care for the baby ( $47.4 \%$ or $37 \%)$; stimulate/support/observe/guide the breastfeeding process $(35.9 \%$ or $28 \%)$; the paternal presence in all phases is fundamental (12.8\% or $10 \%)$; help the mother in her chores $(10.3 \%$ or $8 \%)$. The $14.1 \%$ (11) who answered that the father should not participate in the BF process justified their answer saying that they do not need to help/do not have time/could disturb the process/father's participation is not necessary.

Among the interviewed, $100 \%$ of the fathers argued that their baby should be breastfed by the mother, and the reasons given were: BF is important/necessary ( $57.7 \%$ or $45 \%)$; only the mother could give that/it is her role $(28.2 \%$ or $22 \%)$; milk from the mother is safer/healthier ( $11.5 \%$ or $9 \%)$; the love is transmitted during this process (6.5\% or $5 \%)$.

When asked what was the feeling present during the BF process, the men answered: they felt happiness/joy/safety/well-being ( $80 \%$ or $63 \%$ ); they also felt responsible for the process/baby's feeding ( $5.1 \%$ or $4 \%$ ); they did not find breastfeeding a difficult phase (2.6\% or $2 \%)$; others-weird feeling, that they were more experienced than the firsttime mother, feeling of being present ( $9 \%$ or $7 \%$ ) and no answer $(7.7 \%$ or $6 \%)$. Half the fathers had discussed with the mother of their child their opinion about breastfeeding, whereas only $39.7 \%$ believed that their opinion about breastfeeding could interfere their partner's opinion regarding breastfeeding for longer/less time. A final suggestion from the interviewed was the creation of a program focused on a higher level of fathers' involvement in breastfeeding, introducing the theme naturally in their leisure time, through information given by community workers or during the antenatal meetings.

\section{Discussion}

In the population studied, $85.9 \%$ were married or in a stable relationship. Papp $(20,012)$ [22] argued that married mothers or those co-habiting with their partners were significantly more inclined to breastfeed for longer, keeping this plan throughout the whole 
first year of the child. A similar result was found in a study by Silva PP et al. (2012) [23] at three months, and Brito et al. (2006) [2] reported that relationship aspects can interfere negatively in breastfeeding. It is likely that fathers in a stable relationship feel safer and more at ease with the changes that occur in a couple's life after the birth of a child. Such safety will be transmitted on to the mother and will ultimately represent a reason for success in breastfeeding and her self-esteem in the role of a mother [23] [24].

Regarding the father's schooling, it was noted that over half of the sample had between six and nine years of completed education, similar to what was found by Silva PP et al. (2012) [23]. According to Robert et al. (2015) [4], the educational level of the father is a predictor associated to the main factor of influence on exclusive BF, which is the paternal support. This probably means that if fathers have more access to information, they are more aware of the benefits of $\mathrm{BF}$, which brings similar results to those found in the studies of Silva PP et al. (2012) [23] and Susin et al. (2008) [16].

Regarding the benefits for the nursing mother and infant, $80.8 \%$ of the participants answered that if the mother chooses to breastfeed, she can have the following benefits: strengthening of bond mother-child, prevention of diseases/breast cancer, weight loss, faster recovery post-birth/less chances of complications. These results were contradictory to those found in the study by Silva BT et al. (2012) [5] who reported that in the father's view, the mother is not usually thought of as benefiter, but provider of the baby's food. Although in the present study not all the benefits of breastfeeding to the mother were mentioned, such as a faster uterine involution and reduced risk of breast cancer, the fact that some benefits were indeed mentioned, in comparison with the previous study, shows a possible change in the profile of fathers regarding their knowledge of the subject, although it is still necessary to widen this knowledge.

A study by Arora et al. (2000) [25] says that the father's education about the benefits of breastfeeding has an impact on the number of mothers choosing to breastfeed, also suggesting that this education should take place during the antenatal period and the baby's first quarter. In consonance, Pisacane et al. (2005) [11] affirms that the American Academy of Paediatrics clearly indicates the need for the paternal education and that this should be the " $11^{\text {th }}$ step" for successful BF.

In the present study, $69.2 \%$ of the fathers participated in the antenatal meetings during pregnancy. However, $20.4 \%$ of those who were present in the antenatal meetings were not approached, or had any advice or guidance about breastfeeding. This data reflect the present context of health assistance and highlights the importance of training aimed at an active paternal inclusion in the puerperal pregnancy.

In some studies [5] [24], the fathers were not requested by the professionals during the antenatal appointments. According to Kenosi et al. (2011) [15], 82.1\% feel excluded from the antenatal, and Laanterä et al. (2010) [3] reported that these fathers received little information from the antenatal appointments. Even if they had the intention to support, they faced difficulties such as time of the meetings and pregnancy groups which were incompatible with their work schedule. In the results presented by Silva $P P$ et al. (2012) [23], the number of participants in the meetings was lower than in the present study, as around half the fathers (49.1\%) followed their partners in the antenatal 
appointments. Very similar data affirms that approximately one third of the fathers received some information about breastfeeding [24] [26], which infers that the best period for including the father in the breastfeeding process is during the antenatal.

Those fathers who participated in the breastfeeding period by helping the process corresponded to $80.8 \%$, corroborating with the most recent research on the subject. However, there are controversies with what had been reported in previous research, such as Piazzalunga et al. (2009) [24], who argued that the male participation in the care of children and home, generally, is still seen as eventual or inexpressive. The comparison of the latter with the present study shows that there are positive changes of paternal behaviour and attitudes regarding the BF process. Piazzalunga et al. (2009) [24] introduces the concept of the new paternity, with the father being more present and directly involved with his child, more accessible and responsible for the upbringing of his offspring.

Silva BT et al. (2012) [5] report that the paternal participation in breastfeeding is permeated by doubt and even imposition. Therefore, the men are only able to offer support through positive verbalization and not by actions, besides adopting a prejudiced attitude in relation to the public exposure during breastfeeding. Other studies [2] [21] [27] have demonstrated that men recognize their need to be more effective in their participation. On a study conducted by Susin et al. (2008) [16] 93.3\% of the mothers declared that they would like to have more help from their partners during breastfeeding. Silva PP et al. (2012) [23] say that $78 \%$ of the mothers mentioned that their partners supported breastfeeding and $82.4 \%$ reported an active participation of the father in BF.

In the results presented, $100 \%$ of those interviewed considered that their child should be breastfed, a higher result than that obtained by Garcia-Fragoso et al. (2013) [18], and a high probability of success when the father is favourable [25] [28]-[32], showing similarities with the results found by Silva PP et al. (2012) [23], where 95.4\% showed a favourable opinion to breastfeeding. Other studies $[\mathrm{N}, \mathrm{L}, 14, \mathrm{o}]$ show that paternal approval was the most significant factor on the decision to start and continue to breastfeed.

The main reasons found in our research given by the fathers to support breastfeeding were: $\mathrm{BF}$ is important/necessary (57.7\%); only the mother can provide/it is her obligation (28.2\%); $\mathrm{BF}$ is safer/healthier (11.5\%) and bond is established in this process (6.4\%). This confirms the results of Silva PP et al. (2012) [23] where the main reasons mentioned to support breastfeeding were: "it is good for the baby" $(53.8 \%)$, "it is the ideal food" (16.2\%) and "it is good for the child's development". Both studies showed, as the most mentioned reason, the message that $\mathrm{BF}$ is important, necessary and indispensable. Other existing literature [3] [17] [21] show that men believe BF to be the best for the new born and support this process, justifying it by saying that it is a natural and low cost way to feed their child.

The feeling described by the parents regarding the breastfeeding process is described as happiness/joy/safety/well-being in $80 \%$ of the cases, in accordance with the study by Silva BT et al. (2012) [5], where the fathers described feeling happy and wanting to support, whilst at the same time feeling frustrated and excluded. In other works [15] 
[18] [24], feelings of jealousy, rejection, isolation and that breastfeeding disconnects the baby from the father also appears. Rudman et al. (2007) [9], describes the opinion of the women who believe that the fathers are really neglected and excluded from the process, being considered superfluous and disposable, which makes them feel alone and unsupported in the period after birth.

Finally, as a suggestion of those interviewed for this study, in order to demystify the subject of breastfeeding for men, the question was raised about whether there would be a recommendation to create a program for fathers to get more involved in this process. Already described in the literature [11] [28] [33]-[35], studies have concluded that, through interventions with fathers regarding breastfeeding and guidance on how to prevent and manage the difficulties, the success rate for $\mathrm{BF}$ is higher.

A series of studies have been demonstrating the effectivity of interventions with fathers and the duration of BF. Pisacane et al. (2005) [11] verified that the support offered to fathers aimed at demonstrating the practice of breastfeeding and how to manage difficulties resulted in an increased levels of BF at six months (25\% in the Intervention Group and 15\% in the Control Group). The prevalence of starting BF is higher in the group of fathers present in the intervention ( $74 \%$ versus $41 \%$ ), as reported by Susin et al. (2008) [16], in an study conducted in the south of Brazil, revealing that in the intervention group with the fathers, there was a significant decrease in weaning before the $6^{\text {th }}$ month. Besides that, Wolfberg et al. (2004) [28] described an intervention test where it was found that fathers who participated in intervention can positively influence their partners to breastfeed and are able to become adept of the BF practice.

It is important to note that the limitations of this study, which implicated in a decreased potential for analysis and external validity of the research, arose from the fact that the interviews were conducted in a hospital, after the child's birth. This could mean that the visiting/companion fathers were already interested in the subject. This is an inherent limitation of transversal cohort studies, which do not intend to establish a cause and effect relationship, but nevertheless signal the hypotheses about the association being evaluated. The benefits of this study included broadening the knowledge about the role of the father in $\mathrm{BF}$, which could reflect on the importance the mother gives to this process, contributing to the continuation of this practice and benefiting the new-born. Additionally, this was the first study to take into account the father's feelings, knowledge and participation in this important moment for the child's life.

There is a need for further studies about the subject in other regions, in order to formulate guidelines to highlight the importance of the men in the child's and mother's daily routine. However, this study succeeded in broadening the knowledge surrounding this theme with the following conclusions: 1) the fathers do have some knowledge about breastfeeding, however they do not have a deep understanding of the techniques, benefits and characteristics of BF; 2) men are moving away from the role of mere spectators and becoming main actors in the breastfeeding process, characterizing a more caring, effective and expressive participation; 3 ) the positive feeling is predominant among the fathers during BF; 4) the fathers recognize the importance of participating in the child's care, especially in breastfeeding; 5) the participants of the interview supported the idea 
that their children should be breastfed by their own mothers; and finally 6) the fathers wish for more guidance from the health institutions and professionals.

\section{References}

[1] Raeisi, K., Shariat, M., Nayeri, F., Raji, F. and Dalili, H. (2014) A Single Center Study of the Effects of Trained Fathers' Participation in Constant Breastfeeding. Acta Medica Iranica, 52, 694-696.

[2] Brito, R.S. and de Oliveira, E.M. (2006) Maternal Breast-Feeding: Changes Occurred in the Father's Conjugal Life. Revista Gaúcha de Enfermagem, 27, 193-202.

[3] Laanterä, S., Pölkki, T., Ekström, A. and Pietilä, A.M. (2010) Breastfeeding Attitudes of Finnish Parents during Pregnancy. BMC Pregnancy and Childbirth, 10, 79. http://dx.doi.org/10.1186/1471-2393-10-79

[4] Robert, E., Coppieters, V., Swennen, B. and Dramaix, M. (2015) Determinants of Breastfeeding at Maternity in Brussels. Revue Médicale de Bruxelles, 36, 69-74.

[5] Silva, B.T., Santiago, L.B. and Lamonier, J.A. (2012) Fathers Support on Breastfeeding: An Integrative Review. Revista Paulista De Pediatria, 30, 122-130. http://dx.doi.org/10.1590/S0103-05822012000100018

[6] Eni, R., Phillips-Beck, W. and Mehta, P. (2014) At the Edges of Embodiment: Determinants of Breastfeeding for First Nations Women. Breastfeeding Medicine, 9, 203-214. http://dx.doi.org/10.1089/bfm.2013.0129

[7] Brown, A. and Davies, R. (2014) Fathers' Experiences of Supporting Breastfeeding: Challenges for Breastfeeding Promotion and Education. Maternal \& Child Nutrition, 10, 510526. http://dx.doi.org/10.1111/mcn.12129

[8] Kohlhuber, M., Rebhan, B., Schwegler, U., et al. (2008) Breastfeeding Rates and Duration in Germany: A Bavarian Cohort Study. British Journal of Nutrition, 99, 1127-1132. http://dx.doi.org/10.1017/S0007114508864835

[9] Rudman, A. and Waldenström, U. (2007) Critical Views on Postpartum Care Expressed by New Mothers. BMC Health Services Research, 7, 178. http://dx.doi.org/10.1186/1472-6963-7-178

[10] Dennis, C.L., Gagnon, A., Van Hulst, A. and Dougherty, G. (2014) Predictors of Breastfeeding Exclusivity among Migrant and Canadian-Born Women: Results from a MultiCentre Study. Maternal \& Child Nutrition, 10, 527-544. http://dx.doi.org/10.1111/j.1740-8709.2012.00442.x

[11] Pisacane, A., Continisio, G.I., Aldinucci, M., et al. (2005) A Controlled Trial of the Father's Role in Breastfeeding Promotion. Pediatrics, 116, 494-498. http://dx.doi.org/10.1542/peds.2005-0479

[12] Vieira, T.O., Vieira, G.O., de Oliveira, N.F., Mendes, C.M., Silva, L.R., et al. (2014) Duration of Exclusive Breastfeeding in a Brazilian Population: New Determinants in a Cohort Study. BMC Pregnancy and Childbirth, 14, 175.

[13] Van Wagenen, S.A., Magnusson, B.M. and Neiger, B.L. (2015) Attitudes toward Breastfeeding among an Internet Panel of U.S. Males Aged 21-44. Maternal and Child Health Journal, 19, 2020-2028. http://dx.doi.org/10.1007/s10995-015-1714-1

[14] Inoue, M., Binns, C.W., Otsuka, K., Jimba, M. and Matsubara, M. (2012) Infant Feeding Practices and Breastfeeding Duration in Japan: A Review. International Breastfeeding Journal, 7, 15. http://dx.doi.org/10.1186/1746-4358-7-15

[15] Kenosi, M., Hawkes, C.P., Dempsey, E.M. and Ryan, C.A. (2011) Are Fathers Underused Advocates for Breastfeeding? Irish Medical Journal, 104, 313-315. 
[16] Palmqvist, H., Zäther, J. and Larsson, M. (2015) Fathers' and Co-Mothers' Voices about Breastfeeding and Equality-A Swedish Perspective. Women and Birth, 28, e63-e69. http://dx.doi.org/10.1016/j.wombi.2015.03.005

[17] García-Fragoso, L., Jiménez, D., Ortiz, N. and Quintero, M. (2013) Father Attitudes and Knowledge about Breastfeeding. Boletín de la Asociación Médica de Puerto Rico, 105, 37-40.

[18] Rempel, L.A. and Rempel, J.K. (2011) The Breastfeeding Team: The Role of Involved Fathers in the Breastfeeding Family. Journal of Human Lactation, 27, 115-121. http://dx.doi.org/10.1177/0890334410390045

[19] Fletcher, R., Vimpani, G., Russell, G. and Keatinge, D. (2008) The Evaluation of Tailored and Web-Based Information for New Fathers. Child: Care, Health and Development, 34, 439-446. http://dx.doi.org/10.1111/j.1365-2214.2008.00811.x

[20] Mitchell-Box, K. and Braun, K.L. (2012) Fathers' Thoughts on Breastfeeding and Implications for a Theory-Based Intervention. Journal of Obstetric, Gynecologic, \& Neonatal Nursing, 41, 41-50. http://dx.doi.org/10.1111/j.1552-6909.2012.01399.x

[21] Papp, L.M. (2012) The Longitudinal Role of Breastfeeding in Mothers' and Fathers' Relationship Quality Trajectories. Breastfeeding Medicine, 7, 241-247. http://dx.doi.org/10.1089/bfm.2011.0074

[22] Silva, P.P., Silveira, R.B., Mascarenhas, M.L.W., et al. (2012) The Maternal Perception on Paternal Support: Influence on the Duration of Breastfeeding. Revista Paulista de Pediatria, 30, 306-313. http://dx.doi.org/10.1590/S0103-05822012000300002

[23] Piazzalunga, C.R.C. and Lamounier, J.A. (2009) The Paternity and Its Influence on Breastfeeding. Pediatria, 31, 49-57.

[24] Arora, S., McJunkin, C., Wehrer, J. and Kuhn, P. (2000) Major Factors Influencing Breastfeeding Rates: Mother's Perception of Father's Attitude and Milk Supply. Pediatrics, 106, e67.

[25] Maycock, B., Binns, C.W., Dhaliwal, S., Tohotoa, J., Hauck, Y., Burns, S., et al. (2013) Education and Support for Fathers Improves Breastfeeding Rates: A Randomized Controlled Trial. Journal of Human Lactation, 29, 484-490. http://dx.doi.org/10.1177/0890334413484387

[26] Susin, L.R.O. and Giugliani, E.R.J. (2008) Inclusion of Fathers in an Intervention to Promote Breastfeeding: Impact on Breastfeeding Rates. Journal of Human Lactation, 24, 386392. http://dx.doi.org/10.1177/0890334408323545

[27] Maycock, B.R., Scott, J.A., Hauck, Y.L., Burns, S.K., Robinson, S., et al. (2015) A Study to Prolong Breastfeeding Duration: Design and Rationale of the Parent Infant Feeding Initiative (PIFI) Randomised Controlled Trial. BMC Pregnancy \& Childbirth, 15, 159. http://dx.doi.org/10.1186/s12884-015-0601-5

[28] Wolfberg, A.J., Michels, K.B., Shields, W., O’Campo, P., Bronner, Y., et al. (2004) Dads as Breastfeeding Advocates: Results from a Randomized Controlled Trial of an Educational Intervention. American Journal of Obstetrics \& Gynecology, 191, 708-712. http://dx.doi.org/10.1016/j.ajog.2004.05.019

[29] Sherriff, N., Panton, C. and Hall, V. (2014) A New Model of Father Support to Promote Breastfeeding. Community Practitioner, 87, 20-24.

[30] Mitchell-Box, K.M. and Braun, K.L. (2013) Impact of Male-Partner-Focused Interventions on Breastfeeding Initiation, Exclusivity, and Continuation. Journal of Human Lactation, 29, 473-479. http://dx.doi.org/10.1177/0890334413491833

[31] Karande, S. and Perkar, S. (2012) Do Fathers' Attitudes Support Breastfeeding? A CrossSectional Questionnaire-Based Study in Mumbai, India. Indian Journal of Medical Sciences, 66, 30-39. 
[32] Hunter, T. and Cattelona, G. (2014) Breastfeeding Initiation and Duration in First-Time Mothers: Exploring the Impact of Father Involvement in the Early Post-Partum Period. Health Promotion Perspectives, 4, 132-136.

[33] Abbass-Dick, J., Stern, S.B., Nelson, L.E., Watson, W. and Dennis, C.L. (2015) Coparenting Breastfeeding Support and Exclusive Breastfeeding: A Randomized Controlled Trial. Pediatrics, 135, 102-110. http://dx.doi.org/10.1542/peds.2014-1416

[34] Bich, T.H., Hoa, D.T. and Målqvist, M. (2014) Fathers as Supporters for Improved Exclusive Breastfeeding in Viet Nam. Maternal and Child Health Journal, 18, 1444-1453. http://dx.doi.org/10.1007/s10995-013-1384-9

[35] Ozlüses, E. and Celebioglu, A. (2014) Educating Fathers to Improve Breastfeeding Rates and Paternal-Infant Attachment. Indian Pediatrics, 51, 654-657.

http://dx.doi.org/10.1007/s13312-014-0471-3

\section{Submit or recommend next manuscript to SCIRP and we will provide best service for you:}

Accepting pre-submission inquiries through Email, Facebook, LinkedIn, Twitter, etc. A wide selection of journals (inclusive of 9 subjects, more than 200 journals)

Providing 24-hour high-quality service

User-friendly online submission system

Fair and swift peer-review system

Efficient typesetting and proofreading procedure

Display of the result of downloads and visits, as well as the number of cited articles

Maximum dissemination of your research work

Submit your manuscript at: http://papersubmission.scirp.org/ 